\title{
Digital Subprime: Tracking the Credit Trackers
}

\section{Joe Deville}

\begin{abstract}
This chapter introduces a phenomenon I call 'digital subprime'. This is a domain that represents a rapidly developing frontier in lenders' quest for predictive power involving a growing group of wellfunded technology startups who are entering subprime, payday lending markets in various different countries and are lending at high rates of interest to borrowers who often have either poor credit histories or, in some cases, no credit histories at all. In this new variant of consumer credit lending, we see the exploitation of diverse forms of online data, processed through forms of algorithmic analysis, in the attempt to better predict the repayment behaviour of individuals. This data often appears extremely mundane and to have very little to do with the credit product in hand. Data points can range from a user's IP (Internet Protocol) address, to the particular browser they use, to their screen resolution, to information accessed via social media accounts. In examining this new economic phenomenon, the paper presents results from a project that uses digital methods to try to track the trackers being deployed. The chapter seeks to map the terrain of possibility represented by the diverse forms of data that are rendered accessible to lenders, partly as a basis for future research, and partly to highlight key developments in the present and future ontologies of money.
\end{abstract}

Keywords: Money, debt, payday lending, big data, credit scoring, financialisation

Sure, there is money in credit. But there is so much more growing besides. (Maurer, 2014: 517)

This chapter introduces a particularly ragged edge of debt involving companies seeking to exploit sets of social and technical relations that often, on the face of it, appear to bear quite little connection to finance. I call this assortment of socio-economic practices 'digital subprime'. In introducing this phenomenon, I hope to provide a window into how a small but expanding set of startup businesses, in competition with both each other and the wider credit market, are attempting to refashion monetary ontologies, and in particular the relationship between money and credit.

In the study of money and credit, there is, as Bill Maurer notes above, now something perhaps a little quaint about dwelling on their interdependence - that, on the one hand, all money is dependent on relations of credit and, on the other, that there is money to be made in and from credit. This mutually reinforcing relationship is of course not unimportant. Given the degree to which recent histories have been twisted around the relations and obligations of debt, it is hopefully no longer necessary to outline in too much detail its impact on a variety of registers of contemporary life, ranging across the most intimate and embodied to the most global and abstract. Suffice it to say that, alongside their self-evident role in amplifying a diversity of forms of material deprivation and, for far fewer, profit, relations of credit and debt are: pervasive and utterly everyday (Allon, 2010; Deville and Seigworth, 2015; Langley, 2008), powerful, historically deep-rooted and far reaching (Graeber, 2011; Lazzarato, 2012), playing a direct role in destabilising nation states and democratic processes (as recent Greek history has vividly 
demonstrated; see also Streeck (2011)), undeniably implicated in the amplification of a range of kinds uncertainty and anguish (Davies et al., 2015; Fitch et al., 2011) as well as cruelly misdirected optimism (Berlant, 2011), at least partly responsible for the routine invocation of particular modes of individualised, entrepreneurial subjectivity (Langley, 2008; Marron, 2009), while at the same time, in part through the quasi-alchemy of securitisation and leverage (Allon, 2015a; Montgomerie, 2009), exacerbating social cleavages of various kinds. ${ }^{1}$ It is through all these manifestations of debt, and many others besides, that money asserts not just its relevance to experience and social conduct, but its ability to in many cases radically transform life's quality and in some cases its liveability. Simultaneously, modern money is critically dependent on and feeds off a myriad of relations and credit-like social obligations (Allon, 2015b; Grossberg et al., 2014; Ingham, 2004). These are then variously transformed, to a degree via technologies of commensuration, into the relations of credit that shape a myriad of monetary ontologies. ${ }^{2}$

The quaintness Maurer identifies stems from the fact that an overly tight focus on the entrenched relations of money and credit carries the risk of missing the diversity of other practices, devices and processes that are increasingly orbiting around and meshed into contemporary forms of money and that allow them to flourish, including those associated with consumer credit, the focus of this paper (see also Allon, 2015b, 2015c). There are the infrastructures of payment transfer, some of which are discussed elsewhere in this book, whose management, and in particular the management of the streams of data involved, can become a substantial source of profit in its own right (Maurer, 2012a, 2012b), as well as the related payment card industry (Deville, 2013b; Stearns, 2011; Swartz, 2014), infrastructures of cash dispensing (Bátiz-Lazo et al., 2014; Bátiz-Lazo and Reid, 2011), and technologies and techniques associated with the management of credit risk and default, whether on the side of the consumer (Langley, 2014) or the organisation (Deville, 2015b; Lazarus, 2013b; Ossandón, 2014; Poon, $2007,2009)$. One could even extend the net to more ephemeral practices, such as the governmental attempts to nurture particular kinds of educated, financially aware monetary citizens (Arthur, 2012; Lazarus, 2013a, 2015; Marron, 2014). Money is self-evidently a social relation. However, it is too easy to make assumptions about this relation might consist of; money is instead a rather ambiguous assemblage (Allon, 2015b, 2015c).

This chapter uses digital subprime as a way of teasing out some of these relations and showing the surprising sets of actors that are put into dialogue. It begins with an overview of some of digital subprime's key features, moves on to look at some of the methodological challenges involved in studying it, before examining some of the specific forms of data that organisations in this domain may be gathering and could gather in future. As I will go on to discuss, the analysis thus rests in part on a speculative approach, concerned above all with mapping a terrain of possibility.

\section{Digital Subprime}

The digital subprime is an expanding, global phenomenon, encompassing new and forthcoming ventures spread over a number of countries in Western and Eastern Europe, in Northern, Central and Southern America, as well as in South Africa, Asia Pacific and Australia. 
While being broadly concerned with the redefinition of conventional credit scoring practices for online lending, the term encapsulates three more specific interlinked tendencies. First, offering loans that are short term and high cost - what are sometimes referred to as payday loans - with a customer base assumed to have poor or non-existent credit histories. Second, the reengineering of forms of online social connectivity and influence-based assessment to determine creditworthiness. And third, the reengineering of forms of data mining and algorithmic analysis. In this sense, the digital subprime can be seen as transferring to the field of credit scoring sets of 'big data' techniques and logics most commonly associated with online marketing, but that are also finding themselves inserted into an increasingly diverse set of practices, as far afield as online dating (Mackinnon, 2016), tracing terrorist payment networks (De Goede, 2012) and librarianship (van Otterlo, 2016).

In the digital subprime, analogous techniques are used to either supplement third party credit ratings, or to replace them altogether. This is at least partly because, for companies targeting subprime or near-prime borrowers, conventional credit records may be particularly unhelpful guides, given that the simple absence of credit data (a 'thin' credit file as it is often known in the industry) can translate into a poor credit score, while in many countries, credit scoring is not as extensive as in North America and many Western European countries.

The techniques of digital subprime involve collecting an array of information about past, present and future users. As well as information that might be gathered from existing databases, sometimes but by no means always including conventional credit scores, this may include data that users often unwittingly 'leak' about their identity and online behaviour, potentially collected using third party online tracking devices, which are then used to help determine creditworthiness. What exactly is being collected in these processes and how tends to remain obscure. This may in turn be bolstered by data that users are incentivised to provide to creditors as they build up a relationship with them over time.

In the USA, ZestFinance is perhaps the most prominent digital subprime company. It was set up by an ex-Google employee and the former Head of Subprime Credit Cards at Capital One. After initially focusing on providing the infrastructure for short-term lending websites it controlled (SpotLoan and Zestcash), in time it shifted its predominant focus to licensing its services to financial service providers. Recently, for example, it revealed a partnership with the lending arm of car manufacturer Ford, Ford Credit (BusinessWire, 2017). In a Tedx talk given early in the company's life, one of its two founders, Douglas Merrill, ${ }^{3}$ provides a summary of the more specific promise that digital subprime companies see in online data:

It turns out that there are hundreds of sources of data, trivially available on the net. And thousands if you include things like web-crawls etc. And if your view is that all data is credit data, you build a piece of mathematics, or in our case a whole bunch of mathematics, that consumes thousands of data points. And of those thousands many are missing, many are wrong, etc, but regardless you build a score. And suddenly you build a score that allows you to figure out people who are maybe not quite good enough to get a subprime credit card, but are a way better credit risk than the payday loan guys. So instead of offering them a $700 \%$ APR borrowing [sic], you can offer them something inbetween. (Merrill, 2012) 
Final Accepted Manuscript. For publication in The Sociology of Debt, edited by Mark Featherstone and published by Policy Press.

While the stated goals of digital subprime companies may differ from one another (whether or not, for instance, claiming that the use such of such techniques translates into lower cost credit products), their work is underpinned by a shared promise: that the algorithmic processing of diverse data, potentially with no clear direct relation to an individual's past relationship with financial products, can provide predictive insight into both the identity of that individual and their propensity to behave in a certain manner.

This promise is one that has been highly successful in attracting investors. I will give just a few examples, of what is becoming an increasingly diffuse global marketplace. Let's start with ZestFinance. To date, it has received investments of likely well over $\$ 100$ million (both debt and equity), including from PayPal co-founder Peter Thiel, while also having run tests with a major unnamed US credit card provider and is expanding into China, helped most recently by presumably major, although undisclosed, investment by the Chinese search and web services company Baidu (Lippert, 2014; Lohr, 2015; Russell, 2016). In increasingly moving away from the business of lending directly to instead offering its services to others, it mirrors one of its rivals Big Data Scoring, which '[works] with lenders of all kinds - some of the largest banks in the world, payday lenders, P2P lending platforms, microfinance providers, leasing companies, insurance providers, e-commerce platforms and telecoms' (Big Data Scoring, 2018). There is also Elevate Credit, reportedly recipients of \$70million debt financing (Glasner, 2016), which has been similarly associated with a reliance on 'big data' in scoring potential borrowers, including drawing on information about users' social media accounts as part of its fraud prevention and creditworthiness assessments (Adams, 2013; Loten, 2016; Yu et al., 2014). Elevate Credit also has a UK presence as the payday lender Sunny, where until recently it sat in competition with Wonga, a payday lender most commonly known for the controversies around its historically high interest rates (see below). Wonga attracted early investment of over $f^{7} 70$ million (Moules, 2011) and expanded its interest to additional operations in Poland, South Africa and Spain, although in 2018 its UK business went into administration, as explored below. A further global player is German-based Kreditech, which has raised at least $\$ 150$ million with Thiel surfacing once more as an investor (Anon, 2015; Lunden, 2015, 2016). It has active operations in the Czech Republic, Mexico, Poland, Russia and Spain (Kreditech, 2018). Some notable if smaller members of the group are LenddoEFL, a company resulting from the merger of a Lenndo and Entrepreneurial Finance Lab and with main offices in Bermuda and Singapore, as well as UK and US-based HelloSoda and LendUp, which operates in various US states. These aim to develop credit scoring systems which variously combine data on borrowers from a variety of sources beyond just using conventional credit scores to determine creditworthiness. For those operations that lend directly, the cost of the loans varies. US products tend to range between $250 \%$ and $700 \%$ APR, a range within which most Kreditech loans also find themselves, while Wonga's UK borrowers currently pay just over $1,500 \%$ (UK). ${ }^{4}$

\section{Problems of Method}

Digital subprime is a component of the credit industry that remains underexplored. The majority of insights in this area stem from broadly journalistic accounts (Jeffries, 2011; Lewis, 2011; Shaw, 2011; Pollock, 2012; White, 2012; e.g. Cookson and Moore, 2013; Morozov, 2013; Lippert, 2014; Lohr, 2015; Wilhelm, 2018), with some of the most detailed scholarly assessments 
Final Accepted Manuscript. For publication in The Sociology of Debt, edited by Mark Featherstone and published by Policy Press.

of such practices being reports by advocacy organisations, focusing broadly on consumer protection issues (Mierzwinski and Chester, 2014; Yu et al., 2014). ${ }^{5}$ Recent academic studies have, however, begun to explore the implications of scoring practices more deeply. This includes their potential impact on how reputation and 'good' character are understood (Rosamond, 2016), how they newly delimit the 'value' of certain unbanked populations, thus instituting new forms of visibility and hence governability (Aitken, 2017), and the implications such techniques have for the regulation of credit scoring (Hurley and Adebayo, 2016).

The continued lack of detailed scrutiny of these practices is no doubt in part due to them presently occupying a niche socio-economic domain. Even if their reach is expanding, they remain a small part of the larger domain of payday lending and micro-finance, itself a form of 'fringe finance' (Aitken, 2014). With the digital subprime we are then perhaps at the fringes of the fringe.

Perhaps a more significant issue, however, is the double bind facing the researcher interested in such practices. First, there is the imperative not to become swept up by the hype around big data. As much as such techniques promise analytical power, and as much as this promise is drawn on by those looking to sell their analytical services, they can be readily implicated in the revelation of utterly spurious patterns (boyd and Crawford, 2012). Moreover, as noted above, it is a particular feature of online organisations seeking to harness the power of abundant data to rely to a greater or lesser extent on a range of third party devices and services whose insights are then potentially combined, including with whatever data and analysis the organisation itself has access to. I will come onto the details of this in due course; for now it is important to simply note that big data analysis in such cases is not a cohesive entity, but rather a highly heterogeneous exercise, involving a distributed combination of technologies and methods (Madsen, 2015; Marres, 2012). Before jumping to conclusions about their scope and power we should, as John Law and Evelyn Ruppert point out, try harder to attend to 'the lives and specificities of devices and data themselves' (2013: 10-11).

One of the challenges in doing so, however, relates to a second perhaps greater issue confronting researchers interested in the logics of big data analytics: the frequent and deliberately performed opacity of such techniques. As in many such domains, the precise techniques digital subprime companies employ are carefully guarded trade secrets. It is in the interests of the organisations producing these new forms of credit scoring to keep the details of how they are profiling potential borrowers from competitors, to the extent that it has been argued that this characteristic opacity poses significant consumer protection issues (Mierzwinski and Chester, 2014; Schmitz, 2014; Yu et al., 2014). This is a major barrier to understanding exactly what is being done with the data that is collected.

One response is to attempt to retrieve and analyse the sorts of data that digital subprime companies are themselves using, as Persis Yu, Jillian McLaughlin, and Marina Levy (2014) attempted to in the US. In their case this involved requesting and purchasing information from data brokers - these are organisations that combine data from various sources, including from the behaviour of individuals who are browsing online and are tracked as they move around different sites (more on this later), and then sell this information to third parties, including to digital subprime customers. Their conclusion was that such information, when compared to 
Final Accepted Manuscript. For publication in The Sociology of Debt, edited by Mark Featherstone and published by Policy Press.

conventional credit data, was highly inaccurate. For instance, they looked at the data provided to them by the data broker Spokeo on 15 volunteers, which showed high levels of errors when it came to predictions about postal addresses, the identity of family members, and users' social profiles (see figure 1).

Figure 1: Number of study participants (15 total) with mistakes in their data report, by category

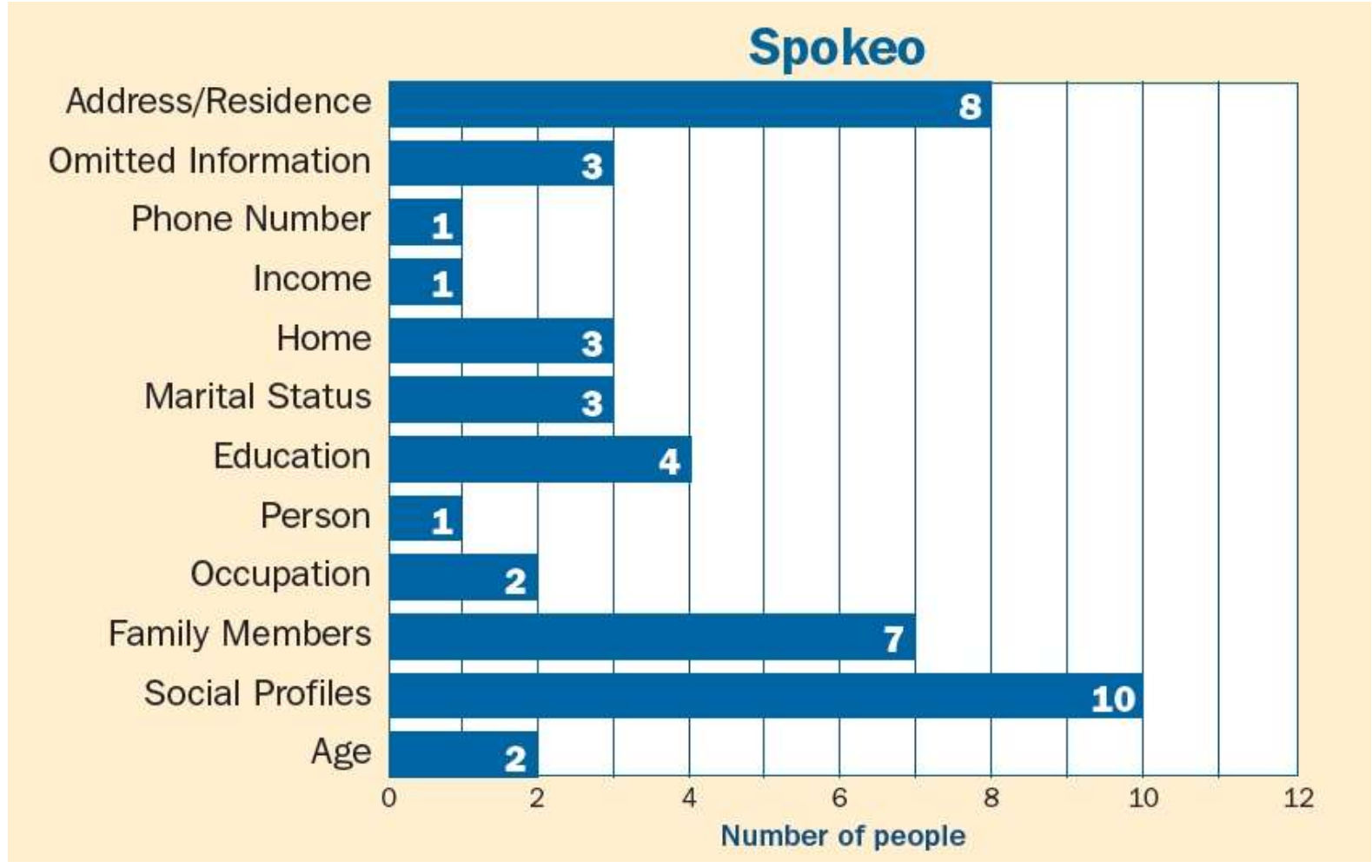

Souce: Yu, McLaughlin, and Levy (2014: 19)

While the authors of this study are quite right to draw attention to the consumer protection issues involved in making credit assessments using data usually utterly opaque to consumers themselves, I would not be so sure that, from the perspective of lenders, this is 'bad data' (Yu et al., 2014: 33). Not only does Spokeo in fact make good predictions in many of the categories being right in a large majority of cases when it comes to quite intimate information such as income, home value, education, and occupation - but also wrong information, in isolation, may not in itself be a barrier to prediction. To reprise Merrill: '... And of those thousands [of data points] many are missing, many are wrong, etc, but regardless you build a score' (emphasis added). The point is not (necessarily) that such companies are unconcerned with accuracy, but that they are concerned first, with combining information from various sources as a way to make up for missing/inaccurate data and then, second, with building scores that they can then test. A score may be used not just to establish a threshold for excluding potentially unreliable debtors, but also as a benchmark, in which predicted borrower behaviour can be compared to how they behave once they are enrolled, as a basis for refining a score in due course.

In the light of both the challenges facing researchers interested in such phenomena and the urgent need to better understand the forms of data that are being collected in such cases, the 
remainder of this paper adopts an approach that is at once empirically grounded and speculative. On the one hand, rather than, as Yu et al. do, looking at the tracking and analytical services that such companies could use it looks at those they do use, using an approach to be explained below. On the other, given the difficulty in knowing exactly what data provided by these third parties are actually fed into the credit scores themselves, the approach is, much like Yu et al.'s, speculative, involving outlining the contours of the landscape of data that might, but also might not, be being drawn upon. This form of what could be called 'speculative empiricism' can be seen as one way of responding to some of the problems of the empirical associated with the widespread proliferation of such techniques (Adkins and Lury, 2009; Burrows and Savage, 2014; Marres and Gerlitz, 2016; Ruppert, 2013; Savage and Burrows, 2007). ${ }^{6}$ It is also hoped that in simply mapping the state of a rapidly evolving and unstable set of practices, where a new approach is created as quickly as another disappears, this research will be of future historical interest. In presenting this research, I draw in part on a project pursued collaboratively with Lonneke van der Velden.

\section{Rendering Visible Algorithmic Practice?}

One response to the opacities of online, big data algorithmic analytics is to seek out moments when what are usually unseen sets of practices become visible. Van der Velden and I have elsewhere explored in greater detail some of the various ways of detecting these often fleeting visibilities (Deville and van der Velden, 2016). I will draw on this for an example, as it provides a particularly helpful way into what may be at stake with such practices. It concerns the now defunct UK payday lender Wonga. For many UK readers, no introduction to Wonga will be necessary. For others, some context: Wonga is often seen as having stood for everything has been wrong with the British subprime lending sector (and here it should be noted that subprime lending practices in the UK have been far more restricted to unsecured lending than mortgage lending). Not only were its interest rates of over $5000 \%$ APR unusually high - although the introduction of a cap on interest rates in 2015 forced it rates down to just over 1,500\% APR many of its other practices came under scrutiny. Its adverts, featuring a cast of rubber faced puppets, were deemed by a number of media commentators to be highly problematic because of their purported potential appeal to younger borrowers, while its debt collection practices and specifically its historic use of 'fake' external collections companies led to censure by the regulator (in this respect, however, they were by no means alone within the broader UK credit industry (Deville, 2015a)).

Likely as a result of a combination of these controversies and the impact of regulatory changes on this industry, Wonga, for some time the most prominent and largest payday lender in the UK, went into administration in August 2018. Elsewhere, Liz McFall and I have explored some of the roots of its failures of what we call 'market attachment' (McFall and Deville, 2018). What interests me for now, however, are the infrastructures that it put in place to attempt to secure that attachment. Wonga UK, like many other payday lending companies (whether or not using data scraping techniques), used a particular device to facilitate a borrower's enrolment into its products: two horizontal 'sliders'. The convention in the industry is for the top slider to control a variable loan amount and for the lower slider to control the term of the loan. Through these two devices, users select the characteristics of the loan to be applied for. In Wonga's case, 
in the early stages of our research in 2013, we noticed these sliders exhibiting some unusual behaviour. Their starting position was not constant. Through the conduct of various tests with the help of volunteers based in different locations, we observed that location - we presume determined via the proxy of a user's IP address - appeared to be a variable that shifted the position of the loan amount slider. We also observed a second significant variable: the browser used to access the site (e.g. Firefox, Chrome, Safari, Internet Explorer). We also observed a final variable that had an effect: repeat visits. Over time, after returning to Wonga's homepage on multiple occasions, the starting position of the bottom slider, controlling repayment time, shifted downwards, making the default repayment time being shown shorter.

Although this behaviour was only short-lived (an aborted experiment, perhaps), it is important for what it stands for: first, an interest in collecting information about users from traces they reveal about themselves as they browse and, second, the ambition to use this information to treat potential customers differently.

Why were Wonga doing this? It is possible to speculate that it was doing two things. First, with the shifts in the loan amount displayed, it was potentially examining the efficacy of providing users with different starting 'offers', with higher risk debtors - as measured via this seemly peculiar data - being 'offered' smaller loans and lower risk debtors the reverse. The sliders in this instance were therefore potentially playing a part in Wonga's risk management procedures. Second, it is likely that the repayment time bar was being used as a marketing tool. It is a generic problem for ecommerce sites to convince borrowers to head down what is sometimes called 'the funnel' from browsing to purchase. Indeed, many of the tracking technologies to be discussed are concerned with this. From the perspective of Wonga, it is possible that a user that returns to a site repeatedly but that does not proceed down the funnel is seen as in need of enticing. By pushing the repayment time-bar down over time, a hesitant user is being, in effect, offered an ever-cheaper credit product (given the interest rate is fixed, which is not the case on all such sites). After all, the end goal for most lenders is to elicit not the purchase of a product but an application for one. This, then, would be part of the process of managing the frictions and 'thresholds' that might prevent users applying for credit, very much along the lines explored by James Ash and colleagues (Ash et al., 2018).

It is rare for the results of the behind the scenes algorithmic apparatuses of digital subprime to surface into the domain of the visible in this way - indeed, in Wonga's case it turned out to be quite temporary. In the stead of other such examples are a few tantalising crumbs. In a conversation with the founder of a startup interested in such techniques, I was told that a wellplaced source had in turn revealed that, for Wonga, a user's screen resolution had at one point turned out to be a particularly predictive variable. Or, there is Douglas Merrill's throwaway revelation in an interview for Bloomberg that 'people who filled out the ZestFinance loan application in capital letters are riskier borrowers than those who write in upper- and lowercase'. Then a punchline: 'Merrill says he doesn't know why' (Lippert, 2014); grist to the mill for those who (prematurely) see the agnostic modelling techniques of big data analytics as marking the end of theory (e.g. Anderson, 2008).

While there are certainty challenges in seeing exactly what such companies see, it is nonetheless possible to gain some quite rich insight into their particular 'modes of seeing' 
Final Accepted Manuscript. For publication in The Sociology of Debt, edited by Mark Featherstone and published by Policy Press.

(Madsen, 2015), into how they see, that is. As will now be discussed, it is possible to clearly demonstrate that such companies routinely deploy an array of third-party tracking technologies to monitor visitors, in which there appears to be a consistent interest in trackers that provide rich real time information about their identity and behaviour. Through the repurposing of existing digital tools for social research (Rogers, 2013), we can begin to track these trackers.

\section{Tracking the Trackers}

The repurposed tool in this case is called Ghostery. ${ }^{7}$ It is a browser plugin designed to enable ordinary website users to understand exactly which third party tracking technologies might be running in the background of a site and to prevent them from being loaded if desired. Ghostery is in turn put to work in this research via the 'Tracker Tracker', ${ }^{8}$ which is a tool developed by the Digital Methods Initiative at the University of Amsterdam. The Tracker Tracker makes it possible to analyse large numbers of sites at once, using the Ghostery library (see: van der Velden, 2014). The digital subprime project used it to analyse which tracking devices these sites are using and, potentially, how this changes over time (the latter is not the subject of the present paper). This involved an initial pilot study in 2013 with eight sites that we for various reasons suspected might be involved in the performance of credit assessments using unconventional data sources and a longer twelve month study in 2013 to 2014 of a total of twenty-three sites. ${ }^{9}$

This analysis reveals, unsurprisingly, a plethora of advertising-focused trackers that are common in the domain of online consumption and information provision, used to monitor the mix of online advertising used to drive users to these sites. ${ }^{10}$ Also, it is quite clear that, like many ecommerce companies, digital subprime sites maintain a strong interest in the detailed analysis of the performance of their sites. Take the trackers 'Optimizely', 'New Relic' and 'AB Tasty'. These appeared on a number of the sites in our sample ${ }^{11}$ and can be used to test website design and efficiency. This includes providing clients with tools to conduct and analyse so called 'A/B tests' on a user's experience of different site configurations and the efficiency of software running in the background. A/B tests are commonly concerned with tweaking a user's journey down the funnel towards whatever goal a website owner has - as noted, in the case of digital subprime this is most likely to be towards making an application for credit. It involves the explicit 'in vivo' testing of website configurations by dividing users into test and control groups and analysing the effectiveness of distinct arrangements and designs. Even if a relatively common practice in ecommerce spaces, this is clearly a crucial part of the mix of the digital subprime's particular data-based provision of financial services. Finally, it is also unsurprising to observe the universal use of Google's suite of analytical tracker software. Google provides website owners with an extremely reliable, tried and tested range of real time information, including on information such as predicted location, referral site, device type being used, all of which could potentially be fed into an analysis of user behaviour. It should be noted here that 'real time' is crucial if such data are to be deployed in an algorithmically driven, rapid and automated credit scoring process.

Particularly useful is Ghostery's ability to show the way that many digital subprime sites use more specialised trackers involved in making real time predictions about the identity of users. One tracker of interest is Threatmetrix, which was for a time deployed on Spotloan, the US based payday lending site set up by ZestFinance. ${ }^{12}$ Threatmetrix is above all a tool for its users to 
Final Accepted Manuscript. For publication in The Sociology of Debt, edited by Mark Featherstone and published by Policy Press.

manage the risk of dealing with potentially anonymous online users. Specifically it guards against what it calls 'account takeover' - that is, potentially, an individual employing another users' details, perhaps stolen. Defending against this requires, as they describe it, 'a holistic view of device, identity and behavior of users' (Threatmetrix, 2015). This is achieved through the construction of 'profiles or personas'. The method is to analyse the way people are interacting with the website in question, comparing 'normal and abnormal usage patterns to distinguish between returning customers and cybercriminals. Furthermore, our solution can detect if botnets are involved by looking at the behavior of activities on actual webpages' (ibid.).

So, in the service of screening out potentially risky customers the tracker on the one hand focuses on trying to provide richer information on the user connecting to the website in question based on referring to a set of existing and constantly updating data on how users 'normally' behave in particular situations and, on the other, tries to detect anomalies between who the user is purporting to be and the device (e.g. computer, tablet, phone) being used. From the perspective of the credit industry this interest in accessing a potentially 'truer' (socio-technical) identity makes eminent sense: including in its credit scoring procedures, it, like many other financial services, has a long-standing concern with developing techniques to tie down the identity of its potential users (in its case, potential borrowers). Here we see this concern moving online, where the greater potential for anonymity exaggerates the challenge.

Helpfully, Threatmetrix has provided some more detailed information on exactly how this is done. It includes working to profile users according to the IP address and ISP (Internet Service Provider), including looking to establish the location of an individual, to establish whether they are connecting to the website using a proxy IP address and, if so, to find their 'true' IP address. It also involves a range of other mechanisms to begin to build up a richer profile of the user. These include:

- Browser Profiling: 'the use of HTML, Javascript, Flash or other methods available in the browser in order to profile a device. Information available through the browser includes, but is not limited to, screen resolution, browser type, clock time, time zone, languages and media supported' (ThreatMetrix, n.d.).

- HTTP Profiling: 'extracting additional risk information communicated during the HTTP connection between the client and the server. Such information includes, but is not limited to the types of compression supported, proxy support and language.' (ibid.).

- Operating System Fingerprinting: profiling connection characteristics in real-time 'to accurately determine the operating system, and often version, being used to establish the internet connection' (ibid.).

- TCP Fingerprinting: 'provides information about the type of connection being used, connection speeds, and for more sophisticated approaches, can be used to individually fingerprint devices based on the network protocol stack' (ibid.).

It is not necessary to go into the details of these methods. The key point is simply that a range of what to an average user might seem to be highly mundane technical data are transformed into ways of beginning to tie down her/his identity. Identity in this case becomes partly composed of a range of traces that might be being leaked about the specific configuration of the device in question and the ways this device is establishing a connection to the website in question. The reason that this is particularly important for the present account is that it 
Final Accepted Manuscript. For publication in The Sociology of Debt, edited by Mark Featherstone and published by Policy Press.

highlights the potential that mundane 'leaked' data affords for those that can access it when it comes to assessing the risk of potential borrowers. We also see screen resolution reappearing as a useful piece of data, the allegedly particularly predictive variable used by Wonga. We can at this point speculate a little further about what function it serves. Screen resolution reveals a lot about the precise type of device being used, while also being a data point whose availability is highly consistent, given that it is universally released in order for websites to scale correctly. When it comes to directly incorporating such data into credit assessment processes, it may be that identifying the device also functions as a useful proxy for information about the 'type' (e.g. social class, age) of person applying for credit. As noted earlier, however, data analysts may claim to have little interest in hypothesising about such causal relations.

Wonga themselves in the period of our research used a tool that promises access to some similar information, called Maxymyser. One of the services it provides is again to enable users to optimise the specifics of website design. But it also provides real time information about the type of customers visiting a site. As the company writes in a report (subtitled 'Breaking Down The Key Strategies To Better Identify \& Target Top Customers'), one of the services on offer is to build customer profiles for financial services and to provide information on 'client age range, geo location, single/multiple accounts, account age, account activity' (Maxymyser 2014). In echoes of Threatmetrix's method, data points used to inform such analyses include 'Software/hardware (e.g. browser type)', 'Device type', 'Time of visit (e.g. day, hour)', 'most recent conversion action' (in other words, the behaviour of a user on the site itself, potentially as they move towards making a financial purchase/application), and information about how the user arrived on the site ('Traffic source type' and 'referring URL').

Two other US-based sites, Spotloan and CashnetUSA, used the Quantcast tracker. Alongside delivering targeted advertising, one of the services Quantcast offers its clients is detailed information about its users. Alongside the familiar geographic and site behaviour information is the offer to US clients in particular of real time demographic predictions. Take, for instance, Quantcast's case study of the reviews and online booking service Yelp (see figure 2). What it shows is how Quantcast, acting as a data broker, translates mundane online behaviour into concrete predictions about a range of variables, some of direct use to financial service providers. This includes variables as personal as income, education, and political leanings (as well as age and ethnicity, although under the Equal Credit Opportunities Act, US-based creditors are prohibited from using these as variables in their credit scoring processes (see: Consumer Financial Protection Bureau, 2013)).

Quantcast also makes clear that in doing so it relies on the sheer extent of its tracking activities. Its selling point is the potential to turn its vast presence across a large range of sites mostly in its role as the deliverer of targeted advertising, ${ }^{13}$ into predictions about the characteristics of its users. As they put it, 'We see the average US online user 600 [times] per month — that's equivalent to having coffee with your friend every hour. This intense visibility into online behavior patterns allows us to draw incredibly detailed profiles, even for small user groups' (Quantcast 2015b). If such data were to be fed into a credit scoring algorithm - and once again, we remain in the domain of the speculative - then online consumption activities (broadly 
Final Accepted Manuscript. For publication in The Sociology of Debt, edited by Mark Featherstone and published by Policy Press.

defined) would be becoming transformed into data points in a credit scoring algorithm, something that a user would unlikely to be aware of.

Figure 2. Yelp case study, using June 2015 data.

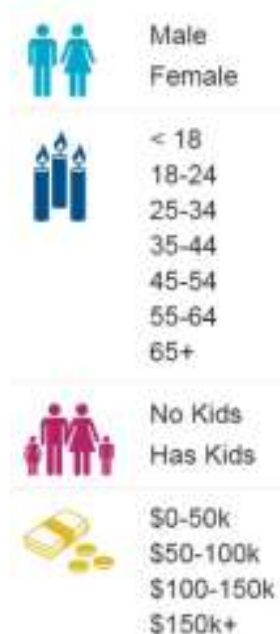

$\$ 150 \mathrm{k}+$

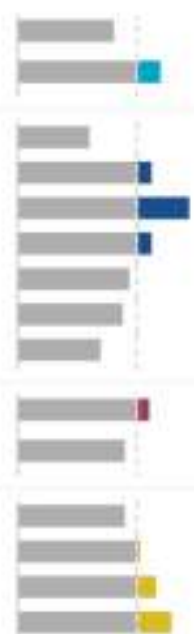

US Averoge
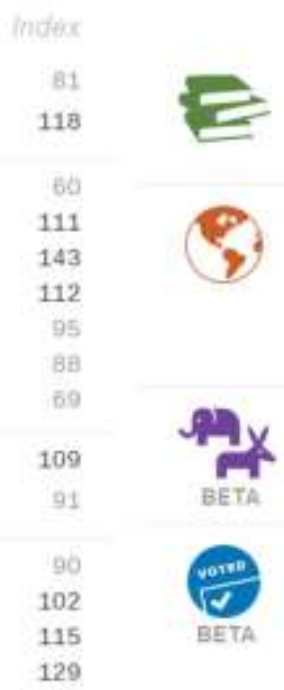

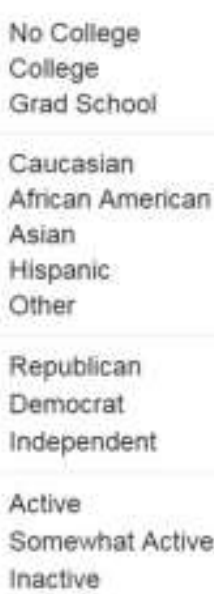

Inactive
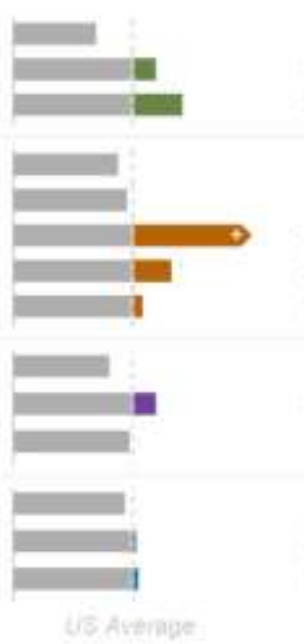

119

141

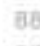

9)

239

132

81

119

98

96

104

Source: Quantcast (2015a)

Part of what such speculative work does, then, is to show (a) the routine presence in this sector of tracking technologies at least designed to deliver this kind of information and (b) the kinds of data that it would be at least feasible to access and, potentially, start to integrate into credit assessment processes.

\section{The Promise of Social Ties}

There is a further dimension to some such analytics: harnessing the information contained in an individual's social ties. Although using very similar principles to other digital subprime companies, Lenddo specialises in basing creditworthiness at least in part on a user's social networks (alongside other 'non-traditional data', including, it claims, 'telecom data', 'browser data', 'mobile data', 'e-commerce transaction data', 'psychometric data', 'form filling analytics' (Lenddo, 2017)). An interview with Lenddo’s founder Jeff Stewart in 2014 gives some insight into the kind of data that it saw as of interest:

What career profiles do your Facebook friends have? What products or restaurants do you (and your friends) Tweet about? [...] [S]ays Stewart: 'If you hang out with people who make a lot of money and pay their bills, then you are more likely statistically to do that.' (Balch, 2014).

As suggested by its recent merger with Entrepreneurial Finance Lab, Lenddo is increasingly focused on trying to sell its method and its software protocols to third parties. It did however lending directly for its first four years of operation, up until 2015 (Balea, 2015). Then it looked to harness the power of social networks more explicitly, by compelling borrowers to obtain references from others in their social network - if the referee was judged positively, this would improve their creditworthiness, as would taking out loans (ibid.). 
Final Accepted Manuscript. For publication in The Sociology of Debt, edited by Mark Featherstone and published by Policy Press.

Both Wonga and Kreditech, meanwhile, at times expressed an interest in harvesting data from Facebook - although this was before the controversies that exploded around the use of similar techniques by Cambridge Analytica and Facebook's impositions of additional restrictions over use of its data by third parties. For instance, on the Polish version of its identikit sites, users visiting its website in 2013 were presented with an incentive - a small discount on the overall cost of their loan - if they installed Kreditech's app on their Facebook account. When doing so, they received the following permission request (and thereafter the obligatory 'Okay?' Yes/No):

Kredito24.pl would like to access your public profile, friend list, email address, custom friends lists, messages, News Feed, birthday, chat status, work history, status updates, checkins, education history, groups, hometown, interests, current city, photos, website, personal description, likes and your friends' birthdays, work histories, status updates, checkins, education histories, events, groups, hometowns, interests, current cities, photos, websites, personal descriptions and likes. (Kredito24.pl, 2013).

If granted, these permissions would have included access to data that might have significantly assisted in the enhancement of predictive capacity. This includes information that could be searched to help confirm the identity of a user, including birthday, hometown, and location. It might also provide insight into information that could supplement or undermine the income level declared by a potential borrower: educational history, work history, as well as relationship details. Further, information such as an individual's 'likes', and indeed those of their friends, could potentially help build up a rich picture of an individual's characteristics to a far greater extent than Quantcast's by comparison rather rudimentary assessment of political preference. A very similar permissions request was at one point also to be found buried in Wonga's html code (see: Deville, 2013a). In fact, in some respects, the request was more intimately intrusive: alongside requesting 'likes', further permissions requested included the user's listed interests, games activity, religious and political views, any subscriptions they might have, and any groups the user was part of. Although a Facebook connection option was not active at the point in 2013 when this code was observed, it had been the year before, accompanied by the claim that connecting 'helps us to know you better. This will improve your chances of being approved for a loan' (Lewis, 2012).

Kreditech also scaled back its interest in Facebook data. By 2014 the request had changed to a request to view a user's 'public profile', without the offer of a discount. This shift is likely to have been in response to a pre-Cambridge Analytica clampdown by Facebook on the unjustified harvesting of data by third party apps (Constine, 2015). For Wonga, meanwhile, perhaps its hesitation was due to an early and prescient recognition of the reputational risks involved. In 2012, for instance, a scandal blew up in Germany over a credit agency's plan to scrape just this kind of data (Hawley, 2012). What certainly remains, however, is the promise offered up to digital subprime companies by social media data: that individuals' intimate preferences and social behaviours as well as, potentially, their locations within wider networks of individuals, can be transformed into data for an assessment of creditworthiness (see also: Morozov, 2013). 
Final Accepted Manuscript. For publication in The Sociology of Debt, edited by Mark Featherstone and published by Policy Press.

\section{Conclusion}

It is tempting to be bleak in assessing the digital subprime's significance, given the potential scope of its tracking activity. It has already been suggested that credit scoring practices represent a form of 'super-panopticism' (Burton, 2008; Leyshon and Thrift, 1999; drawing on Poster, 1995). This would make the digital subprime, with its apparently deeper intrusions into the everyday, implicated in a kind of 'super-super-panopticism'.

At present, however, with reference to the digital subprime sites addressed in this paper, that would be too strong a claim. This is in part because it may be that systems are being developed that use similar logics but that would put the kinds of surveillance being practiced by digital subprime sites in the shade. In particular, it has been revealed that the Chinese government, building on a series of pilot projects, has the ambition develop a population-wide credit score, involving tracking a wide diversity of domains of everyday life and underpinned by intrusive enforcement and punishment mechanisms. The score would be assembled in part via enhanced data sharing between areas including 'public security, civil affairs, human resources and social security, natural resources, housing and urban construction, finance, banking, taxation, industry and commerce, security supervision, securities, science and technology and other such departments', and by extending its gaze potentially to individuals' online browsing and shopping habits (Anon, 2016; see also: Creemers, 2018; Denyer, 2016). But also, when it comes to digital subprime specifically, while a range of high level investors are being motivated to part with considerable sums to underpin its experiments, we need to know more about precisely how the data that are being accumulated about potential borrowers are transformed into concrete predictions and forms of value. Seeking to understand algorithmic calculation from the outside is likely to open up as many questions as answers. This paper is thus in part an injunction to further research, while seeking to make a case for methods and approaches that look to map, as accurately as they can, the state of the terrain and the possibilities it might afford.

At the same time, what this exercise has shown are clear ambitions on the part of digital subprime organisations to reshape present and future ontologies of money and debt in their refashioning of credit scoring. Individuals are to be rendered creditworthy far less according to their demonstrable history with credit products and far more according to an assessment of a set of digital proxies of identity and behaviour, the latter of which may have only the loosest connection to credit and finance. Credit scoring thus appears as an alternately more personal and more abstract affair, sometimes turning its attention to the mundane affects and intimacies of contemporary online life, composed of networks of loose social connections and casually expressed preferences of various sorts (the 'like', most paradigmatically), while, in other moments, recomposing behavioural tendencies through sets of technical data that would seem to most - incorrectly it turns out - to be highly impersonal.

Digital subprime clearly, then, adds to that ever-longer list of industries whose success is predicated on highly dispersed mechanisms of value creation, involving turning a profit out of diverse and only tangentially related data, provided by individuals and ostensibly accessible for 'free' (see: Allon, 2015b). What is perhaps more interesting though is what it adds to the potential futures of money. Money as relation as credit as consumer credit has just maybe found a way of become yet more tightly entangled in the threads daily life, to an extent that would be 
previously unfathomable. This is a monetary future where so-called financialisation extends to a propensity to use one browser or another, or to use devices with a particular screen size, or to CAPITALISE INFORMATION IN APPLICATION FORMS.

How and to what extent all this will come to matter to money, to debt, and to the lives of borrowers remains to be seen. As with all new financial innovations, digital subprime is vulnerable to scandal, to governmental intervention, to consumer resistance, and quite simply to failing to live up to the promises it has been making - we have already seen how a number of its experiments have been shelved or adapted in light of changing socio-political realities. Its future is certainly open. What is also certain, is that it needs to be tracked.

\section{Acknowledgements}

I would like to offer my thanks to Lana Swartz and Manuel Castells for the invitation to the 'Money as Communication' workshop at University of Southern California in October 2014 where an earlier version of this paper was presented and to participants for the very helpful discussion that followed. I am also grateful to the participants of the 'Domesticizing Financial Economies, Part II' mini-conference at SASE in London in June 2015 for further feedback, in particular my commentator José Ossandón. Thanks also to Mark Featherstone, Michael Palm, Lana Swartz, and Lonneke van der Velden for their insightful comments on earlier drafts.

\section{Notes}

${ }^{1}$ This is of course but a small subset of the relevant work on these various topics.

2 This is I realise a reductionist account of the relationship between credit and money. Ingham's detailed account of this is particularly rich, even if it fails to account sufficiently for the processual and materially significant dimensions of monetary becoming (Deville, 2017).

${ }^{3}$ My colleague and I (Deville and van der Velden, 2016) draw on the same quote in a chapter looking in more detail at the methodological problematics studying these companies poses. I return to this chapter at a number of points in the paper.

${ }^{4}$ As I detail later in the chapter, historically the APR of its UK loans was far higher, with rates having peaked at $5843 \%$. This has now changed, with the introduction of a cap on payday lender interest rates in 2015.

5 There is also Wei et al.'s (2016) rather eccentric attempt to quantitatively model the future effects on society of the widespread proliferation of a form of credit assessment based on an analysis of friendship quality, inspired by the social-media based techniques of some digital subprime companies.

${ }^{6}$ Elsewhere the term speculative empiricism has been used by Didier Debaise to refer to a sociological mode of attention influenced by the Gabriel Tarde and Alfred North Whitehead amongst others, who point to the ways in which entities are formed by forces that are not in any straightforward way detectably via empirical registers (there are also parallels here to affect theory). In this instance, I use the term a little more prosaically. That said, given some of my own Whiteheadian leanings (Deville, 2015b), I am happy for this heritage to resonate in the background. I also have in mind Martin Savransky's injunction (influenced by Whitehead) to consider speculation as a 'key ... into a certain pragmatics of thought' (Savransky, 2017). I somewhat basely transpose his response to the problems of the theoretical to the empirical.

7 https://www.ghostery.com

8 https://tools.digitalmethods.net/beta/trackerTracker/. The tool was created in a collaborative project by Yngvil Beyer, Erik Borra, Carolin Gerlitz, Anne Helmond, Koen Martens, Simeona Petkova, JC Plantin, Bernhard Rieder, Lonneke van der Velden, Esther Weltevrede at the Digital Methods Winter School 2012.

9 The 23 sites were: cashnetusa.com, dollarsdirect.ca, dollarsdirect.com.au, fairloanfinancial.com, tcsbank.ru, isepankur.ee, kredito24.cz, kredito24.es, kredito24.mx, kredito24.pl, lenddo.com.co, lenddo.com.ph, lendup.com, plaingreenloans.com, mobiloans.com, netcredit.com, poundstopocket.co.uk, quickquid.co.uk, quickquidflexcredit.co.uk, risecredit.com, spotloan.com, sunny.co.uk, wonga.ca, wonga.co.za, wonga.com, wonga.pl, zaimo.ru. For further details on the method and the pilot project see Deville and van der Velden (2016).

10 These are too numerous to detail here. But more common examples include: Appnexus, Advertising.com, Bidswitch, Doubleclick (owned by Google), Google Adsense, IntelliAd, Tribal Fusion. 
${ }^{11}$ Lenddo, Spotloan, Wonga.

${ }^{12}$ I build here on previous analysis of the function of Threatmetrix in this domain (Deville and van der Velden, 2016), which additionally looks at the QuBit OpenTag tracker. It should be noted that, as far as it is possible to tell, Spotloan stopped using Threatmetrix in mid-2014.

${ }^{13}$ For instance, the targeting of online advertisements based on searches at ecommerce sites - products coming to follow us as we browse is a familiar experience for many of us.

\section{References}

Adams J (2013) Think Finance turns to social media for clues to creditworthiness. Available at: http://www.americanbanker.com/issues/178_12/think-finance-turns-to-socialmedia-for-clues-to-creditworthiness-1055911-1.html (accessed 5 October 2018).

Adkins L and Lury C (2009) Introduction: What is the empirical? European Journal of Social Theory 12(1): 5-20.

Aitken R (2014) Fringe finance: Crossing and contesting the borders of global capital. [S.1.]: Routledge.

Aitken R (2017) 'All data is credit data': Constituting the unbanked. Competition \& Change 21(4): 274-300. DOI: 10.1177/1024529417712830.

Allon F (2010) Speculating on everyday life: The cultural economy of the quotidian. Journal of Communication Inquiry 34(4): 366-381. DOI: 10.1177/0196859910383015.

Allon F (2015a) Everyday leverage, or leveraging the everyday. Cultural Studies 29(5-6): 687-706. DOI: 10.1080/09502386.2015.1017140.

Allon F (2015b) Money, debt, and the business of "free stuff". South Atlantic Quarterly 114(2): 283-305. DOI: 10.1215/00382876-2862718.

Allon F (2015c) On capitalism's emotional logics. In: Progress in Political Economy. Available at: http://ppesydney.net/on-capitalisms-emotional-logics/ (accessed 5 October 2018).

Anderson C (2008) The end of theory: The data deluge makes the scientific method obsolete. Available at: https://www.wired.com/2008/06/pb-theory/ (accessed 5 October 2018).

Anon (2015) Starinvestor Thiel investiert in Hamburger Kreditvermittler Kreditech. In: Manager Magazin. Available at: http://www.managermagazin.de/unternehmen/banken/starinvestor-thiel-investiert-in-hamburgerkreditvermittler-kreditech-a-1041770.html (accessed 5 October 2018).

Anon (2016) Opinions concerning accelerating the construction of credit supervision, warning and punishment mechanisms for persons subject to enforcement for trustbreaking. In: China Copyright and Media. Available at: https://chinacopyrightandmedia.wordpress.com/2016/09/25/opinions-concerningaccelerating-the-construction-of-credit-supervision-warning-and-punishmentmechanisms-for-persons-subject-to-enforcement-for-trust-breaking/ (accessed 5 October 2018). 
Final Accepted Manuscript. For publication in The Sociology of Debt, edited by Mark. Featherstone and published by Policy Press.

Arthur C (2012) Financial Literacy Education: Neoliberalism, the Consumer and the Citizen. Rotterdam: Sense Publishers.

Ash J, Anderson B, Gordon R, et al. (2018) Digital interface design and power: Friction, threshold, transition. Environment and Planning D: Society and Space: 0263775818767426. DOI: 10.1177/0263775818767426.

Balch O (2014) Lenddo's Jeff Stewart: Making online loans to strangers make sense. Available at: http://www.theguardian.com/sustainable-business/lenddo-jeff-stewartmicrofinance-internet-personal-loans (accessed 5 October 2018).

Balea J (2015) Lenddo stops lending, now helps clients determine customer trustworthiness. Available at: https://www.techinasia.com/lenddo-customer-trustworthiness (accessed 16 July 2018).

Bátiz-Lazo B and Reid RJK (2011) The development of cash-dispensing technology in the UK. IEEE Annals of the History of Computing 33(3): 32-45.

Bátiz-Lazo B, Karlsson T and Thodenius B (2014) The origins of the cashless society: Cash dispensers, direct to account payments and the development of on-line real-time networks, c.1965-1985. Essays in Economic \& Business History 32(0): 100-137.

Berlant LG (2011) Cruel Optimism. Durham: Duke University Press.

Big Data Scoring (2018) Big Data Scoring: The leader in big data scoring solutions. Available at: http://bigdatascoring.com/ (accessed 13 July 2018).

boyd danah and Crawford K (2012) Critical questions for big data. Information, Communication \& Society 15(5): 662-679. DOI: 10.1080/1369118X.2012.678878.

Burrows R and Savage M (2014) After the crisis? Big Data and the methodological challenges of empirical sociology. Big Data \& Society 1(1): 2053951714540280. DOI: $10.1177 / 2053951714540280$.

Burton D (2008) Credit and Consumer Society. London: Routledge.

BusinessWire (2017) Ford Credit and Zestfinance team up to enhance risk modeling, better serve consumers and lower credit losses. Available at: https://www.businesswire.com/news/home/20170825005455/en/Ford-CreditZestFinance-Team-Enhance-Risk-Modeling (accessed 13 July 2018).

Constine J (2015) Facebook is shutting down its API for giving your friends' data to apps. In: TechCrunch. Available at: https://techcrunch.com/2015/04/28/facebook-api-shutdown/ (accessed 5 October 2018).

Consumer Financial Protection Bureau (2013) CFPB Consumer Laws and Regulations: Equal Credit Opportunity Act (ECOA). Available at: http://files.consumerfinance.gov/f/201306_cfpb_laws-and-regulations_ecoacombined-june-2013.pdf. 
Final Accepted Manuscript. For publication in The Sociology of Debt, edited by Mark Featherstone and published by Policy Press.

Cookson R and Moore E (2013) Wonga eyes expansion in US and Spain. Available at: https://www.ft.com/content/575363cc-6577-11e2-a3db00144feab49a\#axzz2SDwrNcNy (accessed 5 October 2018).

Creemers R (2018) China's Social Credit System: An Evolving Practice of Control. ID 3175792, SSRN Scholarly Paper, 9 May. Rochester, NY: Social Science Research Network. Available at: https://papers.ssrn.com/abstract=3175792 (accessed 13 July 2018).

Davies W, Montgomerie J and Wallin S (2015) Financial Melancholia. London: Goldsmiths, University of London / Political Economy Research Centre. Available at: http://www.perc.org.uk/perc/wpcontent/uploads/2015/07/FinancialMelancholiaMentalHealthandIndebtedness-1.pdf (accessed 5 October 2018).

De Goede M (2012) 'Smart Targeting' and the Meaning of Money. In: Cultural Anthropology Online. Available at: https://www.culanth.org/fieldsights/335-smarttargeting-and-the-meaning-of-money (accessed 5 October 2018).

Denyer S (2016) China's plan to organize its society relies on 'big data' to rate everyone. Available at: https://www.washingtonpost.com/world/asia_pacific/chinas-plan-toorganize-its-whole-society-around-big-data-a-rating-foreveryone/2016/10/20/1cd0dd9c-9516-11e6-ae9d-0030ac1899cd_story.html (accessed 5 October 2018).

Deville J (2013a) Leaky data: How Wonga makes lending decisions. In: Charisma: Consumer Market Studies. Available at: http://www.charismanetwork.net/finance/leaky-data-how-wonga-makes-lending-decisions (accessed 5 October 2018).

Deville J (2013b) Paying with plastic: The enduring presence of the credit card. In: Gabrys J, Hawkins G, and Michael M (eds) Accumulation: The Material Politics of Plastic. London: Routledge, pp. 87-104.

Deville J (2015a) Inside the world of debt collection. Available at: https://www.opendemocracy.net/ourkingdom/joe-deville/inside-world-of-debtcollection (accessed 5 October 2018).

Deville J (2015b) Lived Economies of Default: Consumer Credit, Debt Collection and the Capture of Affect. London: Routledge.

Deville J (2017) Retrocasting: Speculating about the origins of money. In: Wilkie A, Savransky M, and Rosengarten M (eds) Speculative Research: The Lure of Possible Futures. London: Routledge, pp. 98-110.

Deville J and Seigworth GJ (2015) Everyday debt and credit. Cultural Studies 29(5-6): 615629. DOI: $10.1080 / 09502386.2015 .1017091$.

Deville J and van der Velden L (2016) Seeing the invisible algorithm: The practical politics of tracking the credit trackers. In: Amoore L and Piotukh V (eds) Calculative Devices in a Digital Age. Routledge, pp. 90-109. 
Final Accepted Manuscript. For publication in The Sociology of Debt, edited by Mark Featherstone and published by Policy Press.

Fitch C, Hamilton S, Bassett P, et al. (2011) The relationship between personal debt and mental health: A systematic review. Mental Health Review Journal 16(4): 153-166. DOI: $10.1108 / 13619321111202313$.

Glasner J (2016) CrunchBase Spotlight: Data hints at down rounds, but not wipeout, for marketplace lending. In: TechCrunch. Available at: https://techcrunch.com/2016/07/06/crunchbase-spotlight-data-hints-at-down-roundsbut-not-wipeout-for-marketplace-lending/ (accessed 5 October 2018).

Graeber D (2011) Debt: The First 5,000 Years. Brooklyn, N.Y.: Melville House.

Grossberg L, Hardin C and Palm M (2014) Contributions to a conjunctural theory of valuation. Rethinking Marxism 26(3): 306-335. DOI:

10.1080/08935696.2014.895543.

Hawley C (2012) Critique of German credit agency plan to mine Facebook for data. In: Spiegel Online. Available at: http://www.spiegel.de/international/germany/critique-ofgerman-credit-agency-plan-to-mine-facebook-for-data-a-837713.html (accessed 5 October 2018).

Hurley M and Adebayo J (2016) Credit scoring in the era of big data. Yale Journal of Law and Technology 18: 148-216.

Ingham G (2004) The Nature of Money. Cambridge: Polity Press.

Jeffries A (2011) As banks start nosing around Facebook and Twitter, the wrong friends might just sink your credit. Available at: http://betabeat.com/2011/12/as-banks-startnosing-around-facebook-and-twitter-the-wrong-friends-might-just-sink-your-credit/ (accessed 12 August 2013).

Kreditech (2018) What we do. In: Kreditech. Available at: https://www.kreditech.com/whatwe-do/ (accessed 16 July 2018).

Kredito24.pl (2013) Kredito24. Available at: http://www.kredito24.pl (accessed 20 August 2013).

Langley P (2008) The Everyday Life of Global Finance: Saving and Borrowing in America. Oxford: Oxford University Press.

Langley P (2014) Equipping entrepreneurs: Consuming credit and credit scores. Consumption Markets \& Culture 17(5): 448-467.

Law J and Ruppert E (2013) The social life of methods: Devices. Journal of Cultural Economy 6(3): 229-240. DOI: 10.1080/17530350.2013.812042.

Lazarus J (2013a) De l'aide à la responsabilisation. L'espace social de l'éducation financière en France. Genèses: 76-97.

Lazarus J (2013b) L'Épreuve de l'Argent. Banques, banquiers, clients. Paris: Calmann-Lévy. 
Final Accepted Manuscript. For publication in The Sociology of Debt, edited by Mark. Featherstone and published by Policy Press.

Lazarus J (2015) A la recherche des normes contemporaines de l'argent: elements pour une analyse de la promotion de l'education financiere. Terrains/Théories 1. Available at: http://teth.revues.org/346 (accessed 21 July 2015).

Lazzarato M (2012) The Making of the Indebted Man: An Essay on the Neoliberal Condition. Cambridge Mass.: MIT Press.

Lenddo (2017) Credit Scoring Solution. Lenddo. Available at: https://www.lenddo.com/pdfs/Lenddo_FS_CreditScoring_201705.pdf (accessed 16 July 2018).

Lewis J (2012) Wonga faces questions over borrowing by children. Telegraph.co.uk, 14 October. Available at: http://www.telegraph.co.uk/finance/personalfinance/borrowing/loans/9606570/Wonga -faces-questions-over-borrowing-by-children.html (accessed 5 October 2018).

Lewis T (2011) With Wonga, your prosperity could count on an algorithm. The Guardian, 16 October. Available at: https://www.theguardian.com/money/2011/oct/16/wongaalgorithm-lending-debt-data (accessed 5 October 2018).

Leyshon A and Thrift N (1999) Lists come alive: Electronic systems of knowledge and the rise of credit-scoring in retail banking. Economy and Society 28(3): 434-466.

Lippert J (2014) Lender Charging 390\% Uses Data to Screen Out Deadbeats. Available at: http://www.bloomberg.com/news/articles/2014-10-01/lender-charging-390-uses-datato-screen-out-deadbeats (accessed 5 October 2018).

Lohr S (2015) Zestfinance takes its big data credit scoring to China. Available at: http://bits.blogs.nytimes.com/2015/06/26/zestfinance-takes-its-big-data-creditscoring-to-china/ (accessed 5 October 2018).

Loten A (2016) Online lender Elevate taps fintech vet as CIO. The Wall Street Journal, 25 March. Available at: http://blogs.wsj.com/cio/2016/03/25/online-lender-elevate-tapsfintech-vet-as-cio/ (accessed 31 October 2016).

Lunden I (2015) Sources: Peter Thiel is investing in Kreditech's $\$ 100 \mathrm{~m}$ Series C round. In: TechCrunch. Available at: http://social.techcrunch.com/2015/07/10/kreditech-2/ (accessed 5 October 2018).

Lunden I (2016) Online lender Kreditech closes out Series C at \$103M after getting \$11M from the IFC. In: TechCrunch. Available at: http://social.techcrunch.com/2016/03/23/online-lender-kreditech-closes-out-series-cat-103m-after-getting-11m-from-the-ifc/ (accessed 31 October 2016).

Mackinnon L (2016) Love's algorithm: 'The perfect parts for my machine'. In: Amoore L and Piotukh V (eds) Algorithmic Life: Calculative Devices in the Age of Big Data. London: Routledge, pp. 162-175.

Madsen AK (2015) Between technical features and analytic capabilities: Charting a relational affordance space for digital social analytics. Big Data \& Society 2(1): 2053951714568727 . DOI: 10.1177/2053951714568727. 
Final Accepted Manuscript. For publication in The Sociology of Debt, edited by Mark. Featherstone and published by Policy Press.

Marres N (2012) The redistribution of methods: On intervention in digital social research, broadly conceived. The Sociological Review 60: 139-165. DOI: 10.1111/j.1467954X.2012.02121.x.

Marres N and Gerlitz C (2016) Interface methods: Renegotiating relations between digital social research, STS and sociology. The Sociological Review 64(1): 21-46.

Marron D (2009) Consumer Credit in the United States: A Sociological Perspective from the 19th Century to the Present. New York: Palgrave.

Marron D (2014) "Informed, educated and more confident": Financial capability and the problematization of personal finance consumption. Consumption Markets \&amp; Culture 17(5): 491-511. DOI: 10.1080/10253866.2013.849590.

Maurer B (2012a) Late to the party: Debt and data. Social Anthropology 20(4): 474-481.

Maurer B (2012b) Payment: Forms and functions of value transfer in contemporary society. Cambridge Anthropology 30(2): 15-35.

Maurer B (2014) Postscript: Is there money in credit? Consumption Markets \& Culture 17(5): 512-518. DOI: 10.1080/10253866.2013.850037.

McFall L and Deville J (2018) The market will have you: The arts of market attachment in a digital economy. In: Cochoy F, Deville J, and McFall L (eds) Markets and the Arts of Attachment. Abingdon \& New York: Routledge, pp. 108-131.

Merrill D (2012) Tedx New Wall Street: Douglas Merrill: New credit scores in a new world. Available at:

http://www.youtube.com/watch?feature=player_embedded $\& v=18 \mathrm{CyX} 5 \mathrm{sJ} 5 \mathrm{I}$ (accessed 5 October 2018).

Mierzwinski E and Chester J (2014) Selling consumers, not lists: The new world of digital decision-making and the role of the Fair Credit Reporting Act. Suffolk University Law Review XLVI: 845-880.

Montgomerie J (2009) The pursuit of (past) happiness? Middle-class indebtedness and American financialisation. New Political Economy 14(1): 1-24.

Morozov E (2013) Wonga, Lenddo, Lendup: Big data and social-networking banking. Available at:

http://www.slate.com/articles/technology/future_tense/2013/01/wonga_lenddo_lendu p_big_data_and_social_networking_banking.html (accessed 5 October 2018).

Moules J (2011) Wonga raises $£ 73 \mathrm{~m}$ to feed loan appetite. Financial Times, 16 February. Available at: http://www.ft.com/cms/s/0/1c1fb866-39f3-11e0-82aa00144feabdc0.html\#axzz3gc800R8J (accessed 5 October 2018).

Ossandón J (2014) Sowing consumers in the garden of mass retailing in Chile. Consumption Markets \&amp; Culture 17(5): 429-447. DOI: 10.1080/10253866.2013.849591.

Pollock I (2012) Wonga: What makes money lender tick? Available at: http://www.bbc.co.uk/news/business-18019272 (accessed 5 October 2018). 
Final Accepted Manuscript. For publication in The Sociology of Debt, edited by Mark Featherstone and published by Policy Press.

Poon M (2007) Scorecards as devices for consumer credit: The case of Fair, Isaac \& Company Incorporated. In: Callon M, Millo Y, and Muniesa F (eds) Market devices. Oxford: Blackwell, pp. 284-306.

Poon M (2009) From new deal institutions to capital markets: Commercial consumer risk scores and the making of subprime mortgage finance. Accounting, Organizations and Society (34): 654-674.

Poster M (1995) The Second Media Age. Cambridge: Polity Press.

Rogers R (2013) Digital methods. Cambridge, Massachusetts: The MIT Press.

Rosamond E (2016) “All Data is Credit Data”. Paragrana 25(2): 112-124. DOI: 10.1515/para-2016-0032.

Ruppert E (2013) Rethinking empirical social sciences. Dialogues in Human Geography 3(3): 268-273. DOI: 10.1177/2043820613514321.

Russell J (2016) Baidu invests in ZestFinance to develop search-powered credit scoring for China. In: TechCrunch. Available at: http://social.techcrunch.com/2016/07/17/baiduinvests-in-zestfinance-to-develop-search-powered-credit-scoring-for-china/ (accessed 5 October 2018).

Savage M and Burrows R (2007) The coming crisis of empirical sociology. Sociology 41(5): 885-899. DOI: 10.1177/0038038507080443.

Savransky M (2017) The wager of an unfinished present: Notes on speculative pragmatism. In: Wilkie A, Savransky M, and Rosengarten M (eds) Speculative Research: The Lure of Possible Futures. Oxon and New York: Routledge, pp. 25-38.

Schmitz A (2014) Secret consumer scores and segmentations: Separating "haves" from "have-nots". Michigan State Law Review 2014(5): 1411-1473.

Shaw W (2011) Could Wonga transform personal finance? Available at: http://www.wired.co.uk/magazine/archive/2011/06/features/wonga/page/4 (accessed 3 May 2013).

Stearns DL (2011) Electronic Value Exchange: Origins of the Visa Electronic Payment System. London; New York: Springer.

Streeck W (2011) The crises of democratic capitalism. New Left Review (71). II: 5-29.

Swartz L (2014) Gendered transactions: Identity and payment at midcentury. WSQ: Women's Studies Quarterly 42(1): 137-153. DOI: 10.1353/wsq.2014.0029.

ThreatMetrix (n.d.) Device Fingerprinting and Online Fraud Protection Whitepaper. Available at: http://www.scribd.com/doc/5342718/Device-Fingerprinting-and-OnlineFraud-Protection-Whitepaper\#scribd (accessed 28 July 2015).

van der Velden L (2014) The Third Party Diary: Tracking the trackers on Dutch governmental websites. NECSUS. European Journal of Media Studies 3(1): 195-217. DOI: 10.5117/NECSUS2014.1.VELD. 
Final Accepted Manuscript. For publication in The Sociology of Debt, edited by Mark Featherstone and published by Policy Press.

van Otterlo M (2016) The libraryness of calculative devices: Artificially intelligent librarians and their impact on information consumption. In: Amoore L and Piotukh V (eds) Algorithmic Life: Calculative Devices in the Age of Big Data. London: Routledge.

Wei Y, Yildirim P, Christophe V den B, et al. (2016) Credit Scoring with Social Network Data. Marketing Science 35(2): 234-258.

White MC (2012) Can a payday lending start-up use Facebook to create a modern community bank? Available at: http://business.time.com/2012/11/16/can-a-payday-lending-startup-use-facebook-to-create-a-modern-community-bank/ (accessed 12 August 2013).

Wilhelm C (2018) Big data vs. the credit gap. In: Politico. Available at: http://politi.co/2E75tOs (accessed 16 July 2018).

Yu P, McLaughlin J and Levy M (2014) Big data: A big disappointment for scoring credit risk. March. Boston: National Consumer Law Centre. Available at: https://www.nclc.org/images/pdf/pr-reports/report-big-data.pdf (accessed 5 October 2018). 